\title{
A retrospective analysis of practice patterns in the treatment of methicillin-resistant Staphylococcus aureus skin and soft tissue infections at three Canadian tertiary care centres
}

\author{
John M Conly MD CCFP FRCPC FACP ${ }^{1}$, H Grant Stiver BSc MD FRCPC ${ }^{2}$, Karl A Weiss MD MSc FRCPC ${ }^{3}$, \\ Debbie L Becker MSc${ }^{4}$, Andrew J Rosner BSc MBA ${ }^{4}$, Elizabeth Miller BSc Phm MSc ${ }^{5}$
}

\begin{abstract}
JM Conly, HG Stiver, KA Weiss, DL Becker, AJ Rosner, E Miller. A retrospective analysis of practice patterns in the treatment of methicillin-resistant Staphylococcus aureus skin and soft tissue infections at three Canadian tertiary care centres. Can J Infect Dis 2003;14(6):315-321.
\end{abstract}

BACKGROUND: Methicillin-resistant Staphylococcus aureus (MRSA) infections are increasingly being encountered and pose an increasing burden to the health care system in Canada.

OBJECTIVE: To elucidate and characterize the factors influencing the current MRSA treatment patterns in patients with skin and soft tissue infections (SSTIs) before linezolid became available on the Canadian market.

METHODS: A retrospective study collected demographic, treatment and resource use data on patients hospitalized at one of three geographically distinct tertiary care facilities, where MRSA SSTI treatment was initiated with intravenous (IV) vancomycin. Analysis of opportunities for IV-to-oral switch therapy was based on eligibility criteria.

RESULTS: Of 89 patients identified over a 43-month period, the mean $( \pm S D)$ durations of anti-infective treatment and hospitalization were $22.4 \pm 21$ days and $28.9 \pm 20.8$ days, respectively. An infected surgical wound was most common, representing $62.9 \%$ of infections. The mean duration of vancomycin treatment was 19.5 days and the mean number of $1 \mathrm{~g}$ doses received was $29.0 \pm 32.9$. The majority of patients $(55.1 \%)$ initiated vancomycin therapy a mean of $5.4 \pm 8.9$ days after confirmation of MRSA. Of the $70 \%$ of patients meeting criteria for IV-to-oral switch therapy, only $10 \%$ received oral treatment. The most common reason cited for not switching was lack of an effective oral alternative. Analysis of switch therapy criteria found that IV treatment continued for a mean of 13 days despite the appropriateness of the oral route.

CONCLUSIONS: Considerable variation exists in treatment patterns for MRSA infections. Improvements in the initiation of therapy and the use of IV-to-oral switch therapy may improve care and reduce the duration of hospitalization for MRSA SSTIs.

Key Words: Methicillin-resistant Staphylococcus aureus; Switch therapy; Treatment patterns; Vancomycin

\begin{abstract}
Analyse rétrospective des modalités de traitement des infections de la peau et des tissus mous à Staphylococcus aureus résistant à la méthicilline dans trois centres de soins tertiaires au Canada
\end{abstract}

CONTEXTE : Les infections à Staphylococcus aureus résistant à la méthicilline (SARM) gagnent du terrain et elles imposent un fardeau de plus en plus lourd au système de soins de santé au Canada.

OBJECTIF : Dégager et caractériser les facteurs qui influent sur les modalités actuelles de traitement du SARM chez les patients présentant des infections de la peau et des tissus mous (IPTM) avant l'arrivée du linézolide au Canada.

MÉTHODE : Nous avons procédé, dans le cadre d'une étude rétrospective, à la collecte de renseignements sur des données démographiques de patients hospitalisés, sur les traitements et sur l'utilisation des ressources dans trois centres de soins tertiaires, situés dans des régions géographiques distinctes, où des traitements intraveineux (i.v.) à la vancomycine ont été instaurés pour des IPTM à SARM. L'analyse des possibilités de passage de la voie i.v. à la voie orale reposait sur des critères de sélection.

RÉSULTATS : Chez les 89 patients repérés sur une période de 43 mois, la durée moyenne ( \pm écart-type) du traitement anti-infectieux et de l'hospitalisation a été de $22,4 \pm 21$ jours et de $28,9 \pm 20,8$ jours respectivement. Les plaies opératoires constituaient les sièges les plus fréquents d'infection $(62,9 \%)$. Le traitement à la vancomycine a duré en moyenne 19,5 jours et le nombre moyen de doses de $1 \mathrm{~g}$ administrées a été de 29,0 032,9 . Dans la plupart des cas $(55,1 \%)$, le traitement à la vancomycine a commencé $5,4 \pm 8,9$ jours en moyenne après la confirmation d'une infection à SARM. Soixante-dix pour cent des patients répondaient aux critères de passage de la voie i.v. à la voie orale, mais $10 \%$ seulement d'entre eux ont été soumis à ce type de traitement. La raison la plus souvent invoquée était l'absence de traitement efficace par voie orale. D'après l'analyse des critères de passage, les traitements i.v. se sont prolongés en moyenne de 13 jours malgré la pertinence de la voie orale.

CONCLUSION : Il existe des écarts importants dans les modalités de traitement des infections à SARM. L'amélioration de l'amorce du traitement et le passage de la voie i.v. à la orale pourrait se traduire par une amélioration des soins et une diminution du séjour à l'hôpital.

${ }^{1}$ Division of Infectious Diseases, Department of Medicine, Toronto General Hospital, University Health Network, University of Toronto,

Toronto, Ontario; ${ }^{2}$ Division of Infectious Diseases, Department of Medicine, Vancouver Hospital and Health Sciences Center, University of

British Columbia, Vancouver, British Columbia; ${ }^{3}$ Infectious Diseases and Microbiology, University of Montreal, Hôpital Maisonneuve-

Rosemont, Montreal, Quebec; ${ }^{4}$ Health Economics and Outcomes Research, Innovus Research Inc, Burlington, Ontario; ${ }^{5}$ atient Access and

Outcomes Research, Pharmacia Canada, Mississauga, Ontario

Correspondence and reprints: Dr John Conly, Centre for Antimicrobial Resistance, University of Calgary/Calgary Health Region,

Calgary Laboratory Services, Room 930, North Tower, Foothills Medical Centre, 1403 29th Street NW, Calgary, Alberta T2N 2 T9.

Telephone 403-944-8222, fax 403-944-1095, e-mail john.conly@calgaryhealthregion.ca

Received for publication June 17, 2003. Accepted October 23, 2003 
A ntibiotic resistance is of growing importance to health care systems worldwide, and Canada is no exception (1). Due to the serious nature of emerging antibiotic-resistant pathogens and the limited therapeutic options available to treat them, infections caused by these organisms may be associated with increased morbidity and mortality (2-4) compared with those caused by drug-sensitive organisms, and pose an increasing economic burden to health care systems (5). Among the resistant organisms, methicillin-resistant Staphylococcus aureus (MRSA) is increasingly being encountered in Canadian health care facilities (1). Although the first report of an MRSA isolate in Canada was in 1981 (6), only occasional reports followed. In 1995, the Canadian Nosocomial Infection Surveillance Program (CNISP) began following the incidence of MRSA prospectively and reported an increase from $1 \%$ of all $S$ aureus isolates in 1995 to $8.1 \%$ in 2000 in the health care facilities participating in the CNISP (7). The majority of the increase in MRSA cases has occurred in Ontario and Quebec, followed by British Columbia (7). Although MRSA was initially a hospital-acquired pathogen, it has also recently been recognized as a community-acquired organism (8-11) in Canada, particularly among First Nations peoples.

Because MRSA is often resistant to multiple antibiotics, treatment options may be limited. The usual treatment for serious infections caused by MRSA is vancomycin (12). This antibiotic is available only in the intravenous (IV) form for treatment of these types of infections, and it has the potential for greater toxicity and may be less effective than conventional therapy for infections caused by susceptible staphylococci (5). Furthermore, certain organisms have exhibited increasing rates of resistance to vancomycin, which may limit its usefulness. A Passive Reporting Network established within the CNISP identified 1315 cases of vancomycin-resistant enterococci throughout Canada between 1994 and 1998 (13). In addition, cases of vancomycin-intermediate strains of $S$ aureus have been reported recently in Japan, Europe, Hong Kong and the United States (14-16), although no cases have yet been confirmed in Canada.

Other than intravenous vancomycin, several oral MRSA treatment alternatives are available including trimethoprimsulfamethoxazole, alone or in combination with rifampin; doxycycline; fusidic acid in combination with rifampin; or fluoroquinolones alone or in combination with rifampin, dependent on the susceptibility of the strain. Five years of MRSA surveillance in several hospitals across Canada found resistance rates to ciprofloxacin, trimethoprim-sulfamethoxazole, rifampin and fusidic acid to be $89 \%, 56 \%, 3 \%$ and 3\%, respectively (17). Linezolid, an antibacterial agent available in both IV and oral forms, was approved for use in Canada following the completion of the present study and represents a new option for the treatment of Gram-positive infections, including those caused by MRSA.

Although vancomycin IV has been identified as the current drug of choice for the treatment of MRSA infections, very little is known regarding the real-life practice patterns of treating physicians across Canada. In an effort to gain an understanding of how MRSA infections are currently being treated, we undertook a retrospective study of vancomycin treatment patterns for MRSA infections in geographically distinct regions across Canada, focusing on infections of the skin and soft tissue (SSTIs). Emphasis was placed on determining MRSA treatment characteristics including antimicrobial use, duration of therapy, length of hospital stay (LOS) and use of home IV care services. In addition, an analysis of IV-to-oral switch therapy patterns was conducted to understand the current level of acceptance of the practice, its potential benefits and the barriers to switch therapy in MRSA SSTIs.

\section{METHODS}

A retrospective study was designed based on clinical input from five infectious disease consultants in active practice across Canada (18) and conducted at three tertiary care teaching hospitals from three distinct geographic sites, including the Vancouver Hospital and Health Sciences Centre, Vancouver, British Columbia; the University Health Network, Toronto, Ontario; and Hôpital Maisonneuve-Rosemont, Montreal, Quebec. Written approval of the study protocol was received by the respective institutional ethics review committees at each site before the initiation of the study.

The charts of all patients admitted to hospital between January 1, 1997, and August 31, 2000, and treated with vancomycin IV for an active SSTI caused by MRSA were identified at each site through hospital databases, pharmacy medication records and laboratory records. For the purposes of the study, SSTIs were defined as cellulitis, skin abscess, infected skin ulcer, infected surgical incision, infected traumatic wound, diabetic foot ulcer, decubitus ulcer, ischemic ulcer or infected bite. For the latter four diagnoses, the infection had to involve the soft tissues only, without concomitant osteomyelitis.

All records identified were reviewed for eligibility by study coordinators under the supervision of infectious diseases physicians engaged in active practice. To facilitate concordance in the data collection and abstraction process, study coordinators underwent a training session before the initiation of the study. Data were abstracted from the charts of patients who met all of the inclusion criteria and did not violate the exclusion criteria. Inclusion criteria included the following: hospitalized patients at least 13 years of age with signs and symptoms of an active SSTI suspected or confirmed to be caused by MRSA at the time of vancomycin IV initiation; treatment with at least one dose of IV vancomycin; and hospitalization within one of the study sites. Patients with bacteremia were included provided they did not meet any of the exclusion criteria, which were focused on those with primary bacteremia. Patients were excluded from the study if they had any of the following: infected devices that could not be removed, use of a concomitant systemic corticosteroid, necrotizing fasciitis, gas gangrene, burns to more than $20 \%$ of their total body surface, left-sided endocarditis, osteomyelitis, central nervous system infections, pheochromocytoma, carcinoid syndrome, untreated hyperthyroidism, uncontrolled hypertension, neutropenia (absolute neutrophil count less than 500 cells $/ \mathrm{mm}^{3}$ ), liver disease (total bilirubin greater than five times the upper limit of normal) or enrollment in any clinical trial during the course of the infection. Involvement of an infectious diseases physician in the treatment of each patient was not a requirement for enrollment in the study.

Data for each eligible patient were collected using standardized forms designed for the study. Data collection began on the first day 
of treatment for the SSTI and continued until the infection was successfully treated (ie, resolution or improvement of clinical signs and symptoms of the infection and termination of therapy) in hospital, the patient was discharged to complete therapy at home or until the patient died, whichever occurred first. Parameters collected included basic demographics (age, sex), admission and discharge locations, admission diagnoses, historical and current medical conditions, culture results, start and stop dates of vancomycin IV therapy, details of other antimicrobial therapies (medication, dose, route, and start and stop dates), admission and discharge dates, and use of home IV care services. Data regarding treatments and IV care services received at home were taken from discharge orders, which were assumed to have been followed in full.

In addition to parameters related to the treatment of the infection, the study coordinator determined whether each patient met all the criteria for switch therapy (Table 1). The switch therapy criteria used in the present study were based on the common guidelines currently being used at the participating sites $(19,20)$, which are consistent with other switch therapy guidelines published previously in the literature (21). For patients who met all the criteria, a date on which the criteria were met was recorded and it was determined whether the patient was switched to an oral antimicrobial. If the patient was not switched to an oral agent, a reason was provided by the study coordinator explaining why the patient was not switched, taking into consideration any available susceptibility results, antibiotics available within each institution and other treatment parameters.

To ensure that differences in the patient populations enrolled at the participating sites did not bias the results, statistical testing was conducted before data analysis to compare several baseline patient parameters. Patients were compared on mean age using a paired Student's t-test, and on the proportion of patients with more than two admitting diagnoses, a history of diabetes and a complicated (versus uncomplicated) SSTI using $\chi^{2}$ tests with continuity correction where appropriate.

All patients enrolled in the study were included in the analysis, which was conducted using SAS version 8.01 (SAS Institute, USA). Descriptive statistics (means, SDs, and medians for continuous variables and frequencies for categorical variables) were computed for all demographic and clinical parameters, and the mean duration of hospitalization and of treatment were determined. Because MRSA is generally a nosocomial pathogen, the portion of the hospitalization that might have been attributable to the MRSA infection was determined. An infection treatment LOS was calculated, which represents the number of days between the first day of vancomycin IV treatment and death or discharge.

In addition, the number of IV convertible days, defined as vancomycin IV days that continued past the date that switch therapy eligibility criteria were met, was determined for two groups of patients. First, the number of IV convertible days for patients who switched to an oral anti-infective was calculated to examine the appropriateness of current switch therapy practices. Second, patients who were not switched to an oral anti-infective but were candidates for switch therapy based on the reason provided for not switching were also examined to determine the impact of current barriers to switch therapy in the treatment of MRSA SSTIs. It is important to note that on IV convertible days, no other antibiotics (ie, for polymicrobial infections) were administered via IV.
TABLE 1

Intravenous-to-oral switch therapy criteria

Patients eligible for switch from parenteral to oral therapy (all criteria must be met):

- Patient is tolerating oral or nasogastric (NG) nutrition or receiving medications by mouth or NG tube.

- Patient has a functioning gastrointestinal tract.

- Signs and symptoms related to the infection have resolved or are improving.

- Patient does not fall within the exclusion parameters

Patients to be excluded from consideration for switch therapy:

- Patient has an infection in which continuation of parenteral therapy is indicated, such as infections related to line sepsis with Staphylococcus aureus bacteremia.

- Patient is neutropenic (absolute neutrophil count $<500 / \mathrm{mm}^{3}$ ) and febrile (temperature $>38^{\circ} \mathrm{C}$ ).

- Response to oral medication may be unreliable, for example, in the presence of continuous NG suction, malabsorption syndrome, ileus, protracted vomiting or severe diarrhea.

\section{RESULTS}

A total of 89 eligible patient charts were identified from the medical records at the study sites. Approximately 51\%, 43\% and $7 \%$ of patients were enrolled at the Toronto, Vancouver and Montreal sites, respectively. The relatively low recruitment from the Montreal site was attributed to a large proportion of SSTI patients treated at that hospital having osteomyelitis, an exclusion criteria for the study. A statistical comparison of several baseline characteristics of patients enrolled at the Toronto versus the Vancouver site found that the patients from the two sites were comparable in terms of mean age, the proportion of patients with more than two admitting diagnoses, a history of diabetes and a complicated SSTI.

The demographic and clinical characteristics of patients enrolled in the study are shown in Table 2 . The mean age was 62.2 (SD 15.7) years and almost three-quarters of patients were male. Of the $18.0 \%$ of patients who died during the hospitalization, all were male. Nearly $70 \%$ of patients reported a history of cardiovascular illness, while over one-third of patients reported historical medical conditions of the metabolic/ endocrine and musculoskeletal systems. A large proportion of patients underwent surgery in the six-month period before the MRSA infection, with the majority of surgeries being vascular (eg, aortic aneurysm repair, femoral-tibial bypass) or musculoskeletal (eg, amputation) in nature. The most common type of SSTI reported was an infected surgical incision. Approximately one-half (49.4\%) of all SSTIs were complicated, while the remainder were uncomplicated. MRSA was isolated from the primary infection site in $97.7 \%$ of patients, and also from blood cultures (ie, secondary bacteremia) in 10 patients $(13.5 \%)$. 
TABLE 2

Demographic and clinical characteristics of patients enrolled in the study $(n=89)$

\begin{tabular}{lc}
\hline Mean age in years (SD) & $62.2(15.7)$ \\
Males (\%) & 70.8 \\
Surgery in six months before infection (\%) & 82.0 \\
Deaths during hospitalization (\%) & 18.0 \\
Type of skin and soft tissue infection (\%) & \\
$\quad$ Infected surgical incision & 62.9 \\
Infected skin ulcer & 12.4 \\
Skin abscess & 10.1 \\
Infected diabetic foot ulcer & 4.5 \\
Cellulitis & 3.4 \\
Other & 6.7 \\
Organisms identified by cultures from primary infection site (\%) & \\
$\quad$ MRSA & 96.6 \\
MRSE & 1.1 \\
MRSA and MRSE & 1.1 \\
$\quad$ Undetermined & 1.1 \\
Patients with more than one organism identified (\%) & 18.0 \\
Total treatment duration & \\
Mean days (SD) & $22.4(21.0)$ \\
Median days (minimum, maximum) & $16(1,122)$ \\
Infection treatment length of stay & \\
Mean days (SD) & $28.9(29.8)$ \\
Median days (minimum, maximum) & $17(1,135)$ \\
\hline
\end{tabular}

$\overline{\text { MRSA Methicillin-resistant Staphylococcus aureus; MRSE Methicillin-resistant }}$ Staphylococcus epidermis

The majority of patients were admitted to hospital from private residences $(79.8 \%)$, chronic care institutions $(5.6 \%)$ and rehabilitation centres $(4.5 \%)$, with the remainder of admissions coming from other acute care hospitals (10.1\%). The most commonly reported diagnoses reported at the time of admission involved disorders of the cardiovascular, metabolic/ endocrine, dermatological and musculoskeletal systems. The mean LOS (excluding rehospitalizations) was 49.3 days (SD 49.5 days) with a median of 33 days, ranging from four days to 327 days. The mean LOS for treatment of the MRSA infection was 28.9 days with a median of 17 days (range one day to 135 days). A total of $13.5 \%$ of patients spent time in an intensive care unit during the infection treatment LOS.

In contrast to the $79.8 \%$ of patients who were admitted to hospital from a private residence, only $53.9 \%$ were discharged to a private residence, with an increase observed in the proportion of patients discharged to rehabilitation centres (15.7\%) and chronic care institutions (10.1\%). Following discharge from the initial hospitalization, $5.6 \%$ of patients were readmitted to the same hospital for events deemed to be associated with the SSTI. The mean LOS for rehospitalization was 25.4 days (SD 22.0 days) with a median of 16 days (range four days to 55 days).

The total duration of all anti-infective treatments, defined as the number of days during which any anti-infective treatment was prescribed for the SSTI between the first and last day of anti-infective therapy, was 22.4 days. Table 3 describes the various treatments that contributed to the total duration of
TABLE 3

Anti-infective therapies contributing to the total duration of therapy and the proportion of patients who received each therapy

\begin{tabular}{|c|c|c|c|}
\hline \multirow[b]{2}{*}{ Anti-infective therapy } & \multirow[b]{2}{*}{$\begin{array}{l}\% \text { of patients } \\
(n=89)\end{array}$} & \multicolumn{2}{|c|}{ Days (SD) } \\
\hline & & $\begin{array}{l}\text { Mean } \\
\text { (SD) }\end{array}$ & $\begin{array}{c}\text { Median } \\
\text { (min, max) }\end{array}$ \\
\hline $\begin{array}{l}\text { Anti-infectives initiated before } \\
\text { vancomycin IV } \\
\text { ampicillin (2), ampicillin plus } \\
\text { cefotetan (1), cefazolin (5), } \\
\text { cefoxitin (1), cephalexin (2), } \\
\text { ciprofloxacin (3), ciprofloxacin plus } \\
\text { clindamycin (5), ciprofloxacin plus } \\
\text { metronidazole (2), clindamycin (3), } \\
\text { cloxacillin (6), cloxacillin plus } \\
\text { gentamicin (1), cloxacillin plus } \\
\text { penicillin (2), fluconazole plus } \\
\text { metronidazole (1), levofloxacin (1), } \\
\text { metronidazole (1), metronidazole } \\
\text { plus netilmicin plus rifampin (1), } \\
\text { piperacillin/tazobactam (1), } \\
\text { rifampin (1) }\end{array}$ & $\begin{array}{l}\text { 39.3 } \\
\text { us } \\
\text { is } \\
\text { 1), } \\
\text { 1), }\end{array}$ & $7.6(6.0)$ & $\begin{array}{c}6.5 \\
(2.0,28.0)\end{array}$ \\
\hline Vancomycin IV & 100.0 & $19.5(20.0)$ & $\begin{array}{c}14.0 \\
(1.0,122.0)\end{array}$ \\
\hline \multicolumn{4}{|c|}{ Anti-infectives initiated after vancomycin IV } \\
\hline $\begin{array}{l}\text { Oral anti-infectives } \\
\text { amoxicillin-clavulanic acid (1), } \\
\text { doxycycline (1), ciprofloxacin (2), } \\
\text { ciprofloxacin plus clindamycin (1), } \\
\text { clindamycin (1), metronidazole (2), } \\
\text { trimethoprim-sulfamethoxazole (1) }\end{array}$ & 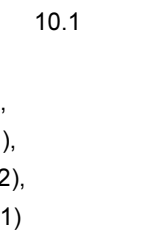 & $11.0(6.8)$ & $\begin{array}{c}10.0 \\
(2.5,24.5)\end{array}$ \\
\hline $\begin{array}{l}\text { Intravenous anti-infectives } \\
\text { cefazolin (1), imipenem (1), } \\
\text { clindamycin plus ciprofloxacin (1) }\end{array}$ & $\begin{array}{l}3.4 \\
)\end{array}$ & $8.3(4.2)$ & $\begin{array}{c}7.0 \\
(5.0,13.0)\end{array}$ \\
\hline
\end{tabular}

Numbers in parentheses are the number of patients who received each therapy (patients might have received more than one treatment). IV Intravenous

therapy and the proportion of patients who received each treatment. There was significant variation in the antimicrobials prescribed both before and after vancomycin IV treatment. In addition to the treatments described in the table, topical anti-infectives (eg, mupirocin ointment or chlorhexidine baths) were administered to one-third (34.8\%) of patients at some point during their systemic antibiotic treatment course.

The mean duration of vancomycin IV treatment was 19.5 days and the mean number of $1 \mathrm{~g}$ doses received was 29.0 (SD 32.9). A comparison of the date of vancomycin IV initiation versus the date of MRSA confirmation showed that the majority of patients $(55.1 \%)$ initiated vancomycin IV therapy after confirmation of MRSA. The mean number of days between MRSA identification and the start of vancomycin IV therapy in these patients was 5.4 days (SD 8.9 days). In $37.1 \%$ of patients, vancomycin IV was initiated a mean of 5.4 days (SD 7.2 days) before confirmation of the MRSA infection. Only $6.7 \%$ of patients had vancomycin IV initiated on the same date as MRSA was confirmed. 
During the course of vancomycin IV treatment, $62.9 \%$ of patients had vancomycin serum levels conducted on at least one occasion. Dose adjustments occurred in $20.2 \%$ of patients, with the number of adjustments ranging from three to six. Reasons provided for dose adjustments included lack of efficacy, renal or hepatic impairment, or nephrotoxicity. While the majority of patients $(83.1 \%)$ completed their entire course of vancomycin IV in hospital, $17 \%$ of patients were discharged while receiving vancomycin IV - almost all (80.0\%) with the assistance of home IV care.

Only $10.1 \%$ of patients switched from vancomycin IV to an oral anti-infective, despite the fact that $69.7 \%$ of patients met all the criteria for switch therapy (Figure 1). Of the patients who met the criteria but did not switch to an oral agent, $82.7 \%$ could have switched based on the reasons provided for not switching. Reasons for not switching among these patients (ie, patients who could have switched but did not) generally fell into one of two categories: no effective oral therapy was available $(n=36)$, or an effective oral therapy was available but not prescribed for unknown reasons $(n=7)$. For the patients who switched to an oral anti-infective, a comparison of the date of switch and the date when the switch criteria were met determined that vancomycin IV therapy continued for a mean of 4.8 days when treatment with an oral agent would have been appropriate. A similar analysis considering the date when switch criteria were met for the patients who could have been switched to an oral agent found that a mean of 14.5 days per patient of vancomycin IV therapy could have been converted to oral therapy days if a suitable oral agent had been available or if the oral agent available had been used.

\section{DISCUSSION}

We undertook the present study to gain an understanding of current treatment patterns for MRSA infections in Canada. Our study focused on patients with SSTIs, which represent a relatively large portion of MRSA-infected patients $(5,7)$. In addition, our data collection included all MRSA patients who met our inclusion criteria who were treated over the past three and a half years at tertiary care hospitals located in geographical regions of Canada where the majority of MRSA cases have been experienced (7). Although our study had a small sample size of 89 patients, we believe that the treatment patterns observed in our study have provided us with the most representative information to date regarding the treatment of MRSA in Canada.

Our study found considerable variation in the treatment of patients with MRSA. The total duration of antimicrobial treatment received by patients ranged from one day to 122 days with a mean of just more than 22 days. This relatively lengthy treatment duration for SSTIs was, in part, due to the use of anti-infectives by almost $40 \%$ of patients before the administration of vancomycin IV. More timely prescribing might also have been achieved if IV vancomycin had been prescribed on positive confirmation of MRSA by culture results. The majority (55\%) of patients did not initiate vancomycin IV therapy until more than five days after MRSA had been identified. The data collected were not able to explain the mean delay of over five days before vancomycin therapy was initiated. However, observations by the site investigators suggested that

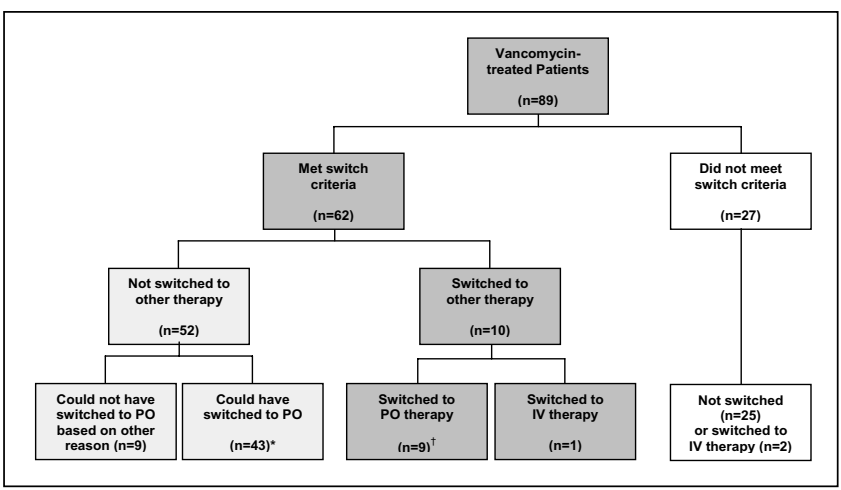

Figure 1) Switch therapy schematic. *Mean (SD) intravenous (IV) convertible days per patient: 14.5 (14.2); ${ }^{\dagger}$ Mean (SD) IV convertible days per patient: 4.8 (9.2)

the primary reason was the delay of the microbiology laboratory to report that the strain was MRSA and the receipt of this result by the attending physician; therapy was often initiated with beta-lactams or other agents specific for MRSA.

Another important observation was the low frequency with which switch therapy occurred. A survey before study initiation found that switch therapy guidelines were in place for each site and that the criteria for switching were almost identical between hospitals (18). Despite the uniformity of switch guidelines and the clinical and economic benefits of switch therapy that have been documented in Canadian hospitals $(19,20,22,23)$, only $10 \%$ of the almost $65 \%$ of patients who could have been switched to oral therapy were actually switched to an oral agent. The main reason cited for not switching eligible patients was that an effective oral therapy was not available. The variability noted in the oral anti-infectives used by the $10 \%$ of patients who were switched supports the notion that there may be uncertainty among prescribers regarding an appropriate oral anti-infective. It is also likely that the lack of routine susceptibility testing to specific oral agents and variation in local resistance rates to oral alternatives when susceptibility testing was performed resulted in the observed variation in treatment selection at each site. Interestingly, although our initial survey documented use of fusidic acid as a possible oral agent (17), it was not documented in the present study. Further exploration of this observation may be warranted.

Among all patients who could have switched to an oral agent, nearly 15 IV days per patient could have been converted to oral therapy days. Even in patients who were switched, an additional five IV days could have been avoided per patient had the switch therapy guidelines been followed to ensure more timely switching. It is possible that among health care professionals responsible for treatment, a lack of confidence in switch therapy guidelines and awareness of its benefits might have contributed to the lack of switching to oral treatment in these patients. Because of the multidisciplinary nature of care received by this patient group, it is also conceivable that a lack of coordination of care and communication between health care providers prevented patients from being considered for switch therapy. Another explanation may be the lack of familiarity of prescribing physicians with oral agents for MRSA 
infections. We did not collect information on whether an infectious diseases physician was consulted to facilitate the management of these patients.

The conversion of all patients eligible for oral therapy could have resulted in earlier discharges. Several studies have demonstrated that early switch strategies have resulted in reduced lengths of stay (24-27) and that shorter hospital durations (ranging from one to 2.4 fewer days) translated into cost savings (25,28-30). Reductions in health care costs ranged from $11 \%$ to greater than $40 \%$ per patient, which, when extrapolated to entire patient populations, may represent significant savings to health care systems.

Given the variability in treatment patterns observed in the present study, the development of guidelines for the treatment of MRSA infections may provide clinical benefits to patients and economic advantages to hospitals. Although a considerable number of treatment guidelines exist in Canada for a variety of infection types (31-34), comprehensive treatment guidelines have not been developed for the treatment of infections caused by MRSA, possibly due to its very recent emergence in Canada (7). Anti-infective treatment guidelines provide health care workers with educational tools to promote the most appropriate use of medications and the best practice of medicine. Our study identified surgical sites as a very prevalent site for MRSA infections, suggesting that physicians who prescribe anti-infectives to this patient group may benefit from treatment guideline information.

\section{REFERENCES}

1. Conly JM, Johnston BL. Antibiotic resistance in Canada at the dawn of the new millenium - a model for the developed world? Can J Infect Dis 2000;11:232-5.

2. Romero-Vivas J, Rubio M, Fernandez C, Picazo JJ. Mortality associated with nosocomial bacteremia due to methicillin-resistant Staphylococcus aureus. Clin Infect Dis 1995;21:1417-23.

3. Holmberg SD, Solomon SL, Blake PA. Health and economic outcomes of antimicrobial resistance. Clin Infect Dis 1987;9:1065-78.

4. Carmeli Y, Troillet N, Karchmer AW, Samore MH. Health and economic outcomes of antibiotic resistance in Pseudomonas aeruginosa. Arch Intern Med 1999;159:1127-32.

5. Kim T, Oh PI, Simor AW. The economic impact of methillinresistant Staphylococcus aureus in Canadian hospitals. Infect Control Hosp Epidemiol 2001;22:99-104.

6. Low DE, Garcia M, Callery S, et al. Methicillin-resistant Staphylococcus aureus - Ontario. Canadian Disease Weekly Report 1981;7:249-50.

7. Conly J. Antimicrobial resistance in Canada. CMAJ 2002;167:885-91.

8. Taylor G, Kirkland T, Kowalewska-Grochowska K, Wang Y. A multistrain cluster of methicillin-resistant Staphylococcus aureus based in a native community. Can J Infect Dis 1990;1:121-6.

9. Embil J, Ramotar K, Romance R, et al. Methicillin-resistant Staphylococcus aureus in tertiary care institutions on the Canadian prairies 1990-1992. Infect Control Hosp Epidemiol 1994;15:646-51.

10. Berlet G, Richards RS, Roth JH. Clenched-fist injury complicated by methicillin-resistant Staphylococcus aureus. Can J Surg 1997;40:313-4.

11. Gardam MA. Is methicillin-resistant Staphylococcus aureus an emerging community pathogen? A review of the literature. Can J Infect Dis 2000;11:202-11.

12. Devlin HR. Bacteria for the nineties. Ostomy Wound Manage 1998;44:32-40.

13. Conly JM, Ofner ME, Paton S, et al. The emerging epidemiology of vancomycin-resistant enterococci in Canada 1993-1998: Results from the Canadian Nosocomial Infections Surveillance Program Passive Reporting Network. Can J Infect Dis 1999;10:38D. (Abst)

14. Hiramatsu K, Aritaka N, Hanaki H, et al. Dissemination in Japanese hospitals of strains of Staphylococcus aureus heterogeneously resistant to vancomycin. Lancet 1997;350:1670-3.

\section{CONCLUSION}

We have shown that considerable variation exists in current treatment patterns for MRSA infections. As the threat of antibiotic resistance continues to grow in Canada, the importance of standardized effective patient management strategies will become even more critical. Our study has identified some of the important factors influencing the prescribing behaviours of physicians, which are key to the development of interventions aimed at providing more clinically effective and economically efficient delivery of health care. The availability and familiarity of effective oral treatment options combined with comprehensive treatment guidelines aimed at all physicians who prescribe antimicrobials may be important steps toward reaching this goal.

ACKNOWLEDGEMENTS: Funding for this study was provided by Pharmacia Canada, Mississauga, Ontario (now Pfizer Canada Inc). The authors wish to thank Dr Walter Schlech III (Queen Elizabeth II Health Sciences Centre, Halifax, Nova Scotia) and Dr Tom Louie (Foothills Medical Centre, Calgary, Alberta) for their contributions to the study design, and Mrs Nancy Ryan (Innovus Research Inc, Burlington, Ontario) for programming all data analysis. We also acknowledge the thorough data collection efforts of the study coordinators, Ms Eileen Halket (University Health Network, Toronto, Ontario), Ms Kenna Sleigh (Vancouver Hospital and Health Sciences Center, Vancouver, British Columbia) and Ms Nathalie Jubinville (Hôpital MaisonneuveRosemont, Montreal, Quebec).

15. Smith TL, Pearson ML, Wilcox KR, et al. Emergence of vancomycin resistance in Staphylococcus aureus. N Engl J Med 1999;340:493-501.

16. Centers for Disease Control. Update: Staphylococcus aureus with reduced susceptibility to vancomycin - United States, 1997. MMWR Morb Mortal Wkly Rep 1997;46:813-5.

17. Simor AE, Ofner-Agostini MO, Bryce E, et al, and the CNISP. The evolution of methicillin-resistant Staphylococcus aureus in Canadian hospitals: 5 years of national surveillance. CMAJ 2001;165:21-6.

18. Conly JM, Stiver GH, Weiss KA, et al. A survey of methicillinresistant Staphylococcal species treatment patterns in Canada. Submitted to Can J Infect Dis.

19. Jewesson P. Cost-effectiveness and value of an IV switch. Pharmacoeconomics 1994;5(Suppl 2):20-6.

20. Zamin MT, Monique MP, Conly JM. Development of an intravenous-to-oral route conversion program for antimicrobial therapy at a Canadian tertiary care health facility. Ann Pharmacother 1997;31:564-70.

21. Rhew DC, Tu GS, Ofman J, Henning JM, Richards MS, Weingarten SR. Early switch and early discharge strategies in patients with community-acquired pneumonia. Arch Intern Med 2001;161:722-7.

22. Frighetto L, Nickoloff D, Martinusen SM, Mamdani FS, Jewesson PJ. Intravenous-to-oral stepdown program: Four years of experience in a large teaching hospital. Ann Pharmacother 1992;26:1447-51.

23. Paladino JA. Pharmacoeconomic comparison of sequential IV/oral ciprofloxacin versus ceftazidime in the treatment of nosocomial pneumonia. Can J Hosp Pharm 1995;48:276-83.

24. Marrie TJ, Lau CY, Wheeler SL, Wong CJ, Vandervoort MK, Feagan BG. A controlled trial of a critical pathway for treatment of community-acquired pneumonia. CAPITAL Study Investigators. Community-Acquired Pneumonia Intervention Trial Assessing Levofloxacin. JAMA 2000;283:749-55.

25. Omidvari K, de Boisblanc BP, Karam G, Nelson S, Haponik E, Summer W. Early transition to oral antibiotic therapy for community-acquired pneumonia: Duration of therapy, clinical outcomes, and cost analysis. Respir Med 1998;92:1032-9. 
26. Hendrickson JR, North DS. Pharmacoeconomic benefit of antibiotic step-down therapy: Converting patients from intravenous ceftriaxone to oral cefpodoxime proxetil. Ann Pharmacother 1995;29:561-5.

27. Siegal RE, Halpern NA, Almonoff PL, Lee A, Cashin R, Greene JG. A prospective randomized study of inpatient IV antibiotics for community-acquired pneumonia: The optimal duration of therapy. Chest 1996;110:965-71.

28. Dietrich ES, Joseph U, Vogel F, et al. Cost-effectiveness of ceftriaxone $1 \mathrm{~g}$ vs second-generation cephalosporins in the treatment of pneumonia in general medical wards in Germany. Infection 1999;27:148-54.

29. Rittenhouse BE, Stinnett AA, Dulisse B, et al. Evaluating the costs of levofloxacin and ceftriaxone in inpatient adults with community-acquired pneumonia. Pharm Ther 1999;24:169-79.
30. Dresser LD, Niederman MS, Paladino JA. Cost-effectiveness of gatifloxacin versus ceftriaxone with a macrolide for the treatment of community-acquired pneumonia. Chest 2001;119:1439-48

31. The Ontario Anti-Infective Review Panel. Anti-infective guidelines for community-acquired infections. 3rd edition. Toronto: Queen's Printer for Ontario, 2001.

32. Health and Welfare Canada. Canadian guidelines for the prevention, diagnosis, management and treatment of sexually transmitted diseases in neonates, children, adolescents and adults. Can Commun Dis Rep 1992;18:88-90.

33. STD treatment guidelines. 1992. **Ottawa?**: Government of Ontario, 1992.

34. Reese RE, Betts RF. A practical approach to infectious diseases. Toronto: Little, Brown \& Company, 1991. 


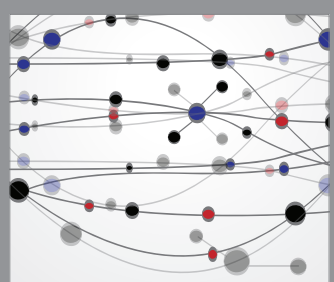

The Scientific World Journal
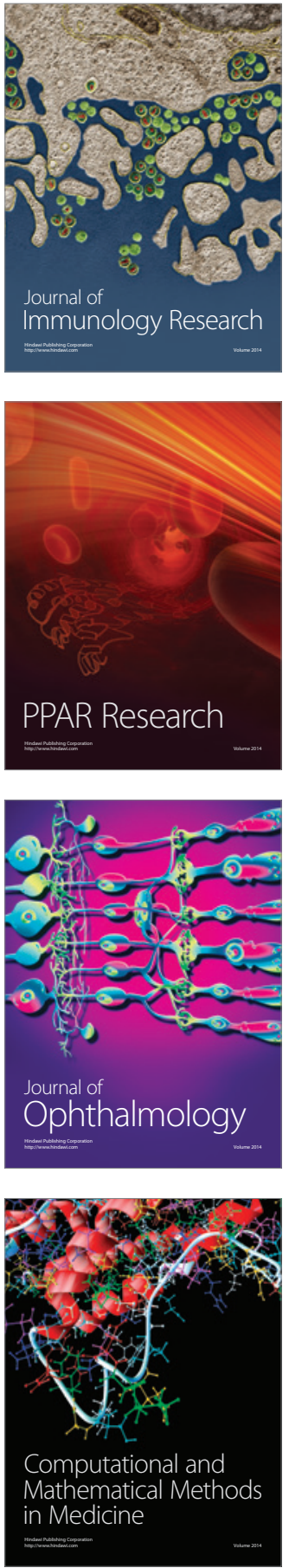

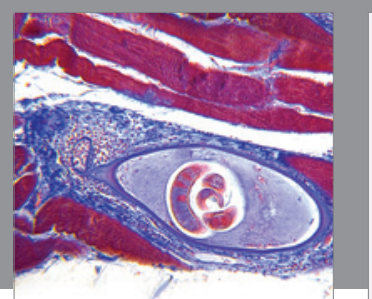

Gastroenterology Research and Practice

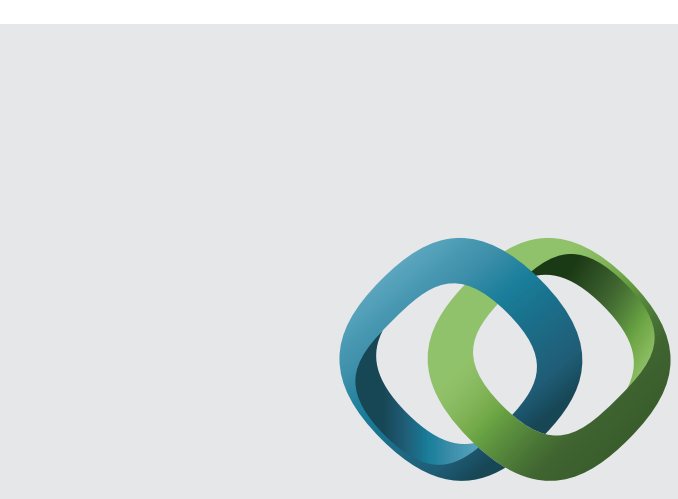

\section{Hindawi}

Submit your manuscripts at

http://www.hindawi.com
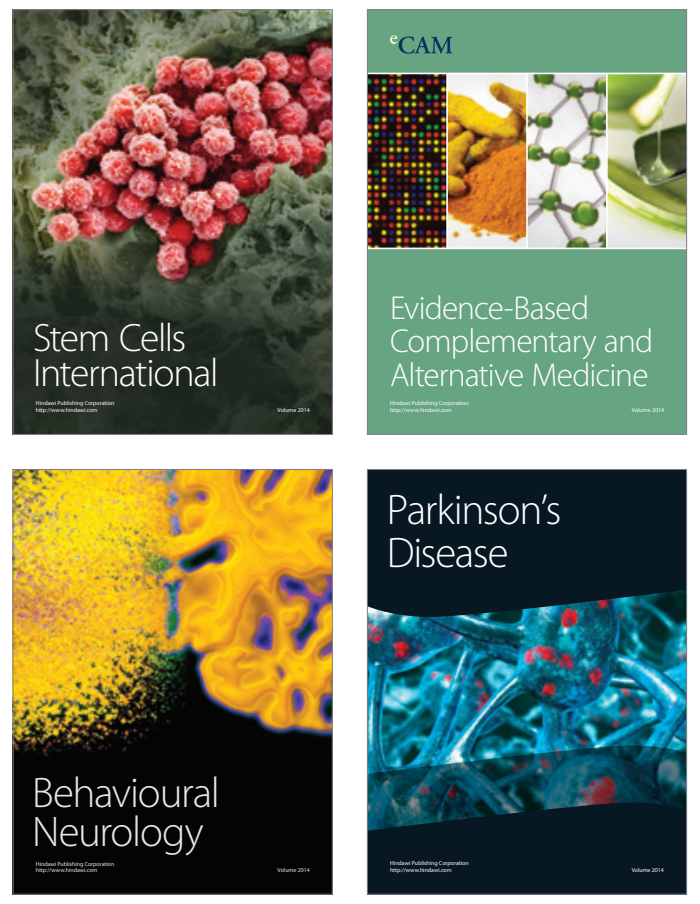
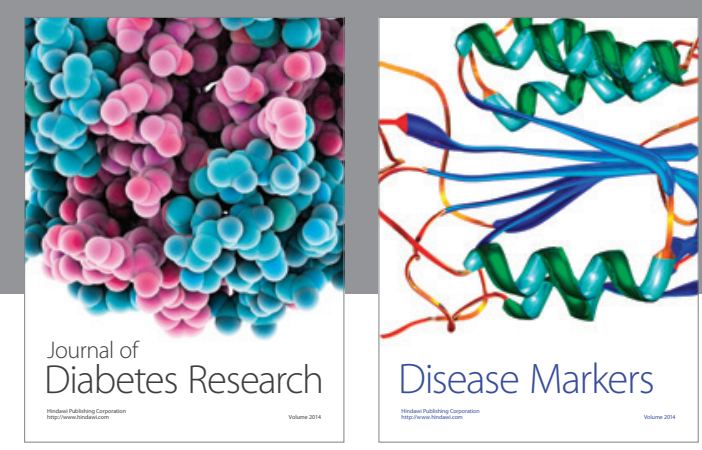

Disease Markers
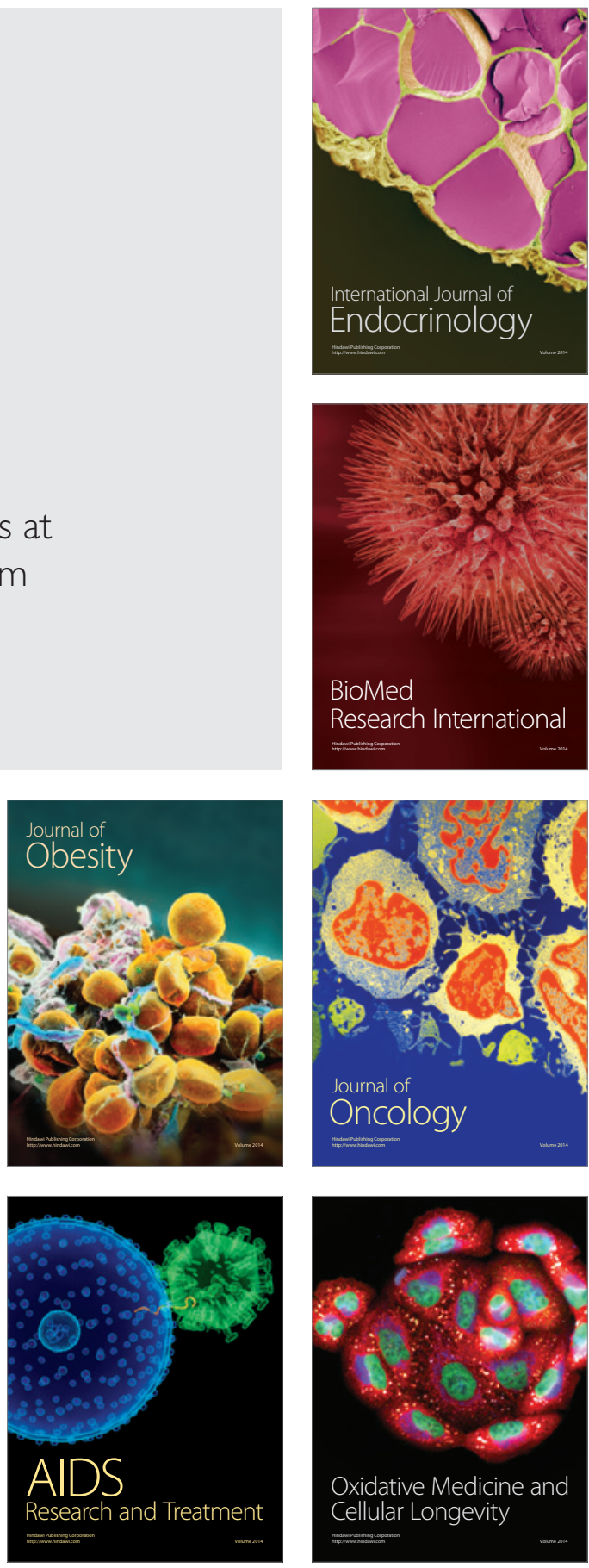